\title{
Strength and Ductility Balance of a Ti-5Al-2Sn-2Zr-4Cr-4Mo (Ti-17) Alloy with Various Microstructures: Experiment and Machine Learning
}

\author{
Hiroaki MATSUMOTO, ${ }^{1) *}$ Daiki TADOKORO²) and Irvin SÉCHEPÉE ${ }^{3)}$ \\ 1) Department of Advanced Materials Science, Faculty of Engineering and Design, Kagawa University, $2217-20$ Hayashi-cho, \\ Takamatsu, Kagawa, 761-0396 Japan. \\ 2) Graduate Student, Kagawa University. Now at Hitachi Metals, Ltd., 2107-2 Yasugi-cho, Yasugi, Shimane, 692-8601 Japan. \\ 3) Graduate Student, Kagawa University, 2217-20 Hayashi-cho, Takamatsu, Kagawa, 761-0396 Japan.
}

(Received on June 8, 2021; accepted on August 10, 2021)

\begin{abstract}
This work examined the tensile properties and hardness of a Ti-5Al-2Sn-2Zr-4Cr-4Mo (Ti-17) alloy having various morphology of an equiaxed, a $(\alpha+\beta)$ bimodal, and a $(\alpha+\beta)$ lamellar (with or without secondary $\alpha$ precipitates) microstructures in terms of an experimental analysis and a machine learning approach. Among the various morphology, a good balance on strength and ductility is obtained in the bimodal morphology. On the strength, higher strength is exhibited in the microstructures having secondary lamellar $\alpha$ precipitates. Here, we experimentally find that the primary $\alpha$ phase of an equiaxed grain or a lamellae acts as only the strengthening according to the rule-of-mixtures, on the other hand, the secondary lamellar $\alpha$ precipitates act as precipitation strengthening dominated by cutting mechanism. On the ductility, it is strongly affected by the difference in morphology and the formation of secondary lamellar $\alpha$ precipitates; high ductility is obtained in an equiaxed grained morphology and in the microstructure with a decreasing fraction of secondary $\alpha$ precipitates. A machine learning approach adapting neural network and clustering (the Ward's method) algorithms successfully predicts the linking between the microstructural factors and the tensile properties of strength, elongation to fracture and reduction of area; a similar dominant mode to the experimental results is estimated from a machine learning approach. Additionally, a quantitative analysis on the effect of each microstructural factor is successfully estimated according to the sensitivity of variable's importance in terms of the neural network algorithm.
\end{abstract}

KEY WORDS: Ti-5Al-2Sn-2Zr-4Cr-4Mo alloy; microstructures; tensile properties; precipitation hardening; machine learning.

\section{Introduction}

One of the serious issues in structural metallic material so as to solve the energy problem and realize a sustainable society is to develop high-strength and light weight structural metallic materials. Titanium alloys are attractive materials for aerospace and automotive applications due to their high strength-density ratio. When the strength increases, the ductility and/or toughness of alloys generally deteriorates with relationship often called a "banana curve". We need to overcome this trade-off relationship between strength and ductility for the enhanced performance of structural metallic alloys.

For the $\mathrm{Ti}$ alloys, the various microstructures have a strong influence on the mechanical behaviors. ${ }^{1)}$ Fine scale

\footnotetext{
* Corresponding author: E-mail: matsumoto.hiroaki@kagawa-u.ac.jp
}

microstructure leads to an increasing of ductility as well as strength. Additionally the refinement of microstructure is effective for retarding crack nucleation and the enhanced superplasticity at high temperature. On the other hand, a coarse grained microstructure is more resistant to creep and fatigue crack growth. Compared to the morphology, the equiaxed microstructures often have high ductility as well as high fatigue strength. While, high fracture toughness and superior resistance to creep and fatigue crack growth are revealed in the lamellar microstructure. For the bimodal microstructure composed of the lamellar and the equiaxed structures, it exhibits a well-balanced property profile. Thus, the variety of microstructural feature at different length scales (alpha/beta fraction, morphology, distribution of the two equilibrium phases, crystal orientation, boundary characteristics, micro-texture) strongly affects the mechanical properties. While, the quantitative understanding of the 
complex linkage between the microstructural feature and mechanical properties among strength, ductility, fatigue property and toughness is still unclear.

Recently it has been placed importance on the approach combined with the data science for accelerating the R\&D of new innovative materials in the world. In Japan, a new concept named "Materials Integration" was proposed. ${ }^{2)}$ This concept is designed to predict the performance from the process linking through the four elements by taking full advantage of computational material science, experiments, database and data science. The data science thanks to a machine/deep learning approach is a programming technique used to automate the construction of analytical models and a process of examining, comparing and modeling data sets and their relationships, thereby, providing prediction of material performance and complicated relationship with high accuracy. According to the research on a machine learning approach for Ti alloys, Collins et al. ${ }^{3)}$ successfully predicted the tensile properties of the Ti-6Al$4 \mathrm{~V}$ alloy by a Bayesian neural network approach. Malinov et al. developed neural network models to predict mechanical properties including fatigue behavior. ${ }^{4}$ Regarding the forging behavior and microstructural evolution of Ti alloys, Wang et al. ${ }^{5)}$ and the present author ${ }^{(6)}$ successfully predicted the linking between the process conditions of forging and the dynamic globularization behavior of the $\alpha$-lamellae. According to Zhichao et al., ${ }^{77}$ grain size evolution during forging of a Ti-6Al-2Zr-1Mo-1V was also successfully linked with processing condition thanks to a machine learning approach. Additionally, plastic flow behavior of the Ti-17 alloy under forging was also successfully predicted by a neural network model. ${ }^{8)}$ Thus, the data science (in combination with machine or deep learning approach) provides a hint for understanding of the complicated relationship among manufacturing conditions, microstructural evolution and mechanical performance.

This work focuses on the quantitative understanding on correlation between microstructures and mechanical properties (strength and ductility) of the Ti alloy in terms of an experimental approach and a machine learning approach. Here, we adopted a Ti-5Al-2Sn-2Zr-4Mo-4Cr (Ti-17) alloy as a model Ti alloy. A Ti-17 alloy is an $(\alpha+\beta)$ Ti alloy practically used primarily for low-temperature aircraft engine applications (fan and compressor disks) owing to its high strength, superior fracture toughness, and excellent creep property. $\left.{ }^{9}\right)$ Recently, Xu et al. ${ }^{10)}$ and Yamabe-Mitarai et al. ${ }^{11)}$ experimentally examined the relationships among the processing parameters, microstructure and tensile properties systematically on the Ti-17 alloy having a lamellar $(\alpha+\beta)$ microstructure. This work will expand the examined microstructures with an equiaxed microstructure, a bimodal microstructure, a lamellar microstructure and a bi-lamellar microstructure for understanding the relationship with the tensile properties systematically and quantitatively. Thus, the present study aims at examining the dominant mode of mechanical properties of the Ti-17 alloy originating from the microstructural factors, which is in terms of both approaches of an experimental analysis and a machine learning approach.

\section{Experimental Procedure}

2.1. Alloys

A Ti-17 alloy with a chemical composition (wt.\%) of Ti-4.89Al-2.00Sn-1.92Zr-3.82Cr-3.93Mo- $(0.09 \mathrm{Fe}-$ $0.014 \mathrm{Si}-0.102 \mathrm{O}-0.01 \mathrm{C}$ ) was used in this research.

\subsection{Heat Treatment Schedule}

Various types of microstructures were prepared by controlling the process conditions by following process schedule of Fig. 1. For obtaining the different type of morphology, heat treatment of an as-received Ti-17 alloy or hot rolling followed by heat treatments was carried out according to the process conditions as illustrated in Fig. 1(a). For obtaining lamellar type microstructures, heat treatment of the as-received Ti-17 alloy having a lamellar microstructure (as shown in the following Fig. 4(a)) was carried out at temperatures ranging from $780^{\circ} \mathrm{C}$ to $950^{\circ} \mathrm{C}$ followed by quenching into oil. Additionally, two step aging at temperatures from $550^{\circ} \mathrm{C}$ to $650^{\circ} \mathrm{C}$ were also carried out for precipitation of fine secondary $\alpha$ from supersaturated $\beta$. For obtaining the equiaxed and bimodal microstructures, the asreceived Ti-17 alloy plates (having the lamellar microstructure) with a thickness of $10 \mathrm{~mm}$ were hot rolled at $850^{\circ} \mathrm{C}$ to be a thickness of $1.3 \mathrm{~mm}$ (hereafter, this hot rolled plate will be called as the $850 \mathrm{HR}$ specimen), followed by controlling the equiaxed microstructures by subsequent heat treatment at similar conditions to the case of the lamellar starting microstructure. Thus, various kinds of microstructures were prepared by controlling the heat treatment conditions.

Additionally, in order to obtain fine secondary $\alpha$ precipitates and control their morphology and size, forging and subsequent aging or forging followed by cooling with changing the cooling rates were carried out at the process

(a)

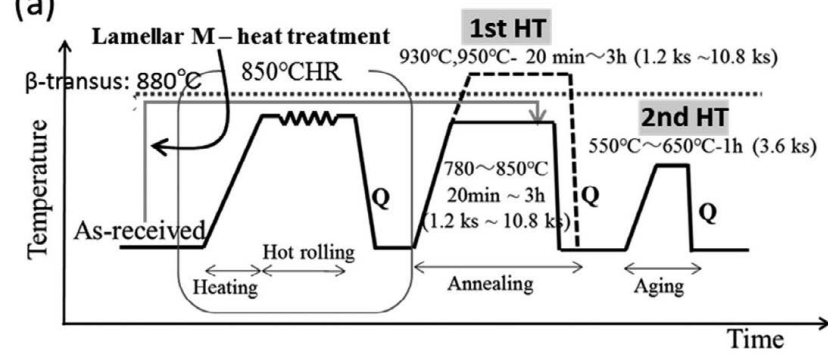

(b)
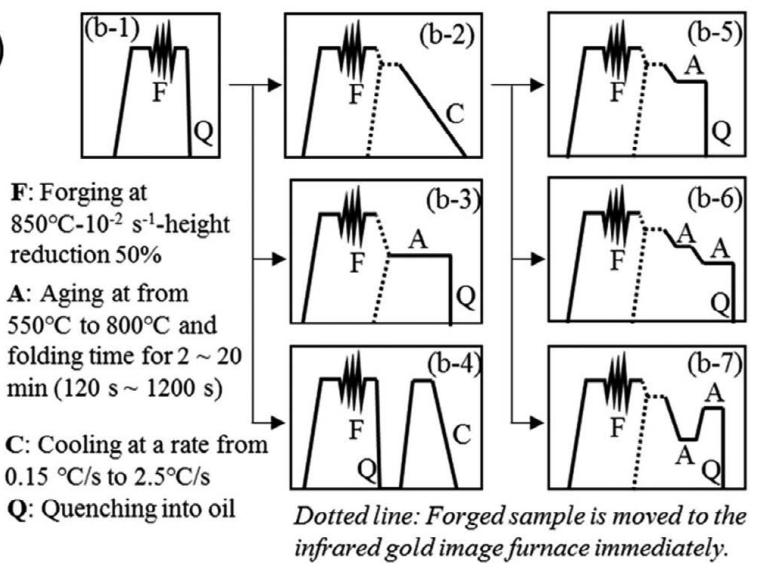

Fig. 1. (a) Process routes for various microstructural formation for the Ti-17(A) alloy. (b) Classification of forging and subsequent aging process for the Ti-17(F) alloy. 
conditions as illustrated in Fig. 1(b). Herein, forging of the Ti-17 specimen ( $5 \mathrm{~mm}$ in diameter and $7.5 \mathrm{~mm}$ in height) is carried out at $850^{\circ} \mathrm{C}$ and strain rate of $10^{-2} \mathrm{~s}^{-1}$ to be a height reduction of $50 \%$ (corresponding to a height true strain of 0.75 ). For controlling the fraction and size of the secondary $\alpha$ precipitates formed from supersaturated $\beta$, cooling rates were changed from $0.15^{\circ} \mathrm{C} / \mathrm{s}$ to $2.5^{\circ} \mathrm{C} / \mathrm{s}$ as (b-2, 4) in Fig. 1(b). Additionally, oil-quenching after forging is carried out for achieving a high cooling rate as (b-1). To control the morphology and size of the secondary $\alpha$ precipitates more extensively, two-step aging according to the $(b-5,6,7)$ was performed.

Hereafter, in order to distinguish the production route clearly, the specimens prepared from conditions of Figs. 1(a) and 1(b) will be designated as the Ti-17 (A) alloy and the Ti-17 (F) alloy, respectively.

Here, 40 specimens for the Ti-17(A) alloy and 42 specimens for the Ti-17 (F) alloy were prepared, respectively.

\subsection{Evaluations on Microstructure and Mechanical Properties}

The microstructures were observed using a JEOL JSM$7001 \mathrm{~F}$ field emission gun scanning electron microscope (SEM) equipped with an Oxford-HKL electron backscatter diffraction (EBSD) detector, and a transmission electron microscope (TEM) (JEOL-JEM 2100F). The OLYMPUSStream software was used on the SEM images to evaluate the microstructural factors (grain size, fraction of $\alpha$ phase, aspect ratio, and so on) quantitatively. For evaluation of the interspacing of primary $\alpha$ phase and secondary $\alpha$ phase, respectively, interspacing between lamellae was measured by selecting the pair of lamellae aligned in parallel and an average value of measurements at 50-100 interspacing was estimated.
Tensile tests in air atmosphere were performed at an initial strain rate of $5 \times 10^{-4} \mathrm{~s}^{-1}$ and at room temperature for the Ti-17(A) alloys. Tensile specimens, with a gauge length of $10.5 \mathrm{~mm}$, a width of $2 \mathrm{~mm}$ and a thickness of $1.2 \mathrm{~mm}$, were machined to be parallel to the final rolling direction of the plates (before heat treatment). Tensile tests were carried out two times or three times for each sample followed by checking the validity of plastic flow behavior and the values of strength and ductility. Additionally, Vickers hardness test was carried out on the Ti-17(A) alloy and the Ti-17(F) alloy under the condition of $9.8 \mathrm{~N} / 10 \mathrm{~s}$ and an average value of ten measurements was adopted for each sample.

\subsection{Machine Learning}

Regression of tensile properties for the Ti-17(A) alloy and classification of microstructural feature for the Ti17(F) alloy were modeled by means of a machine learning approach. Among various machine learning algorithms, this work adopted two algorithms of hierarchical clustering and neural network methods as implemented in the scikit-learn python module (v.0.21.3) ${ }^{12)}$ for the regression and clustering of the experimental data.

\section{Results and Discussion}

\subsection{Microstructures}

Here, we shall report the microstructural features of the Ti-17(A) alloy and the Ti-17(F) alloy as follows.

3.1.1. Microstructures on the Rolled and Heat Treated Specimen (Ti-17 (A) Alloy)

Figure 2 summarizes the typical microstructures shown by SEM-back scattered electron (BSE) images of a lamellar microstructure and an equiaxed microstructure of the

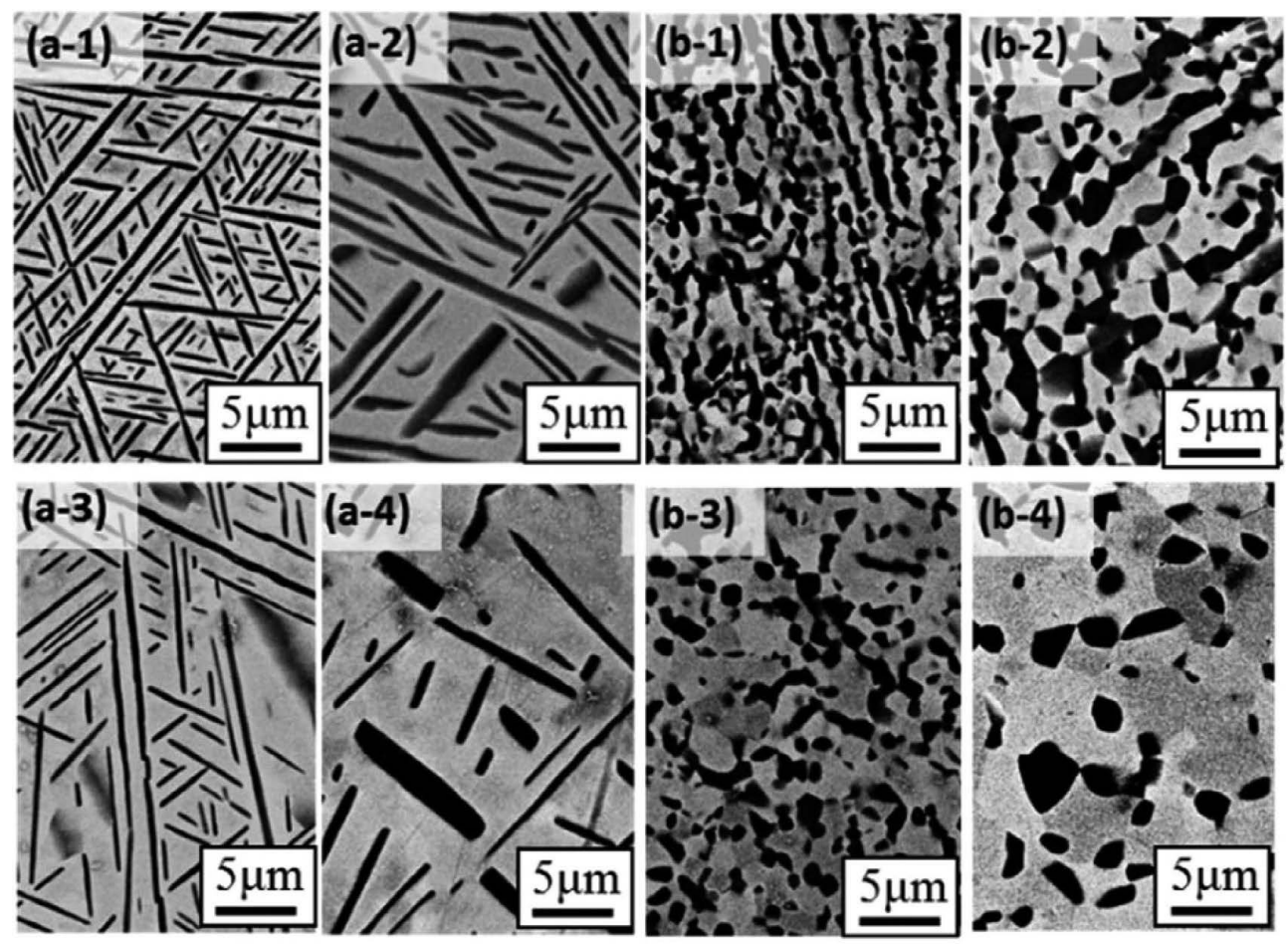

Fig. 2. Typical microstructures of the Ti-17(A) alloy: (a-1-4) heat treated specimens of the as received alloy and (b-1-4) heat treated specimens of the $850 \mathrm{HR}$ specimen. Heat treatment conditions are (a-1)(b-1) $800^{\circ} \mathrm{C}$ and $20 \mathrm{~min}$, (a-2) (b-2) $800^{\circ} \mathrm{C}$ and $3 \mathrm{~h},(\mathrm{a}-3)(\mathrm{b}-3) 850^{\circ} \mathrm{C}$ and $20 \mathrm{~min}$, and (a-4)(b-4) $850^{\circ} \mathrm{C}$ and $3 \mathrm{~h}$, respectively. 
Ti-17 (A) alloys. Figures 2(a-1)-2(a-4) are the lamellar microstructures heat treated at $800^{\circ} \mathrm{C}$ and $850^{\circ} \mathrm{C}$ of the asreceived specimen, respectively. And, the equiaxed microstructures shown in Figs. 2(b-1)-2(b-4) are the result of heat treated specimens of the $850 \mathrm{HR}$ specimen. Here, black phase corresponds to the $\alpha$ phase and white phase does the $\beta$ phase, respectively. With increasing a heat treatment temperature and a holding time, we can observe a coarsening of the width of the $\alpha$ phase and a deceasing of the $\alpha$-aspect ratio and the $\alpha$ fraction for the lamellar microstructures. As similar to this case for the lamellar microstructure, an increasing of heat treatment temperature and holding time results in coarsening of the $\alpha$ phase and a decreasing in the $\alpha$ fraction for the equiaxed microstructures.

In order to obtain the fine secondary $\alpha$ precipitation, a lower temperature aging was carried at $550^{\circ} \mathrm{C}, 600^{\circ} \mathrm{C}$, $650^{\circ} \mathrm{C}$ for $1 \mathrm{hr}$ (as illustrated in Fig. 1(a)) for the solution treated specimens (at temperatures ranging from $780^{\circ} \mathrm{C}$ to $850^{\circ} \mathrm{C}$ ). Figure 3 shows the typical microstructures (after this aging process) of the lamellar (so called as the bilamellar microstructure) and bimodal microstructures having fine secondary $\alpha$ precipitates as acicular shape. From Fig. 3, it can be found that various types of microstructures with the basket-weave secondary $\alpha$ precipitate are obtained in combination with the low-temperature aging.

A quantitative analysis on these microstructures was conducted, followed by a discussion of dominant mode of strength and ductility in relation to these microstructural factors.

\subsubsection{Microstructures on Hot Forged and Heat Treated Specimen (Ti-17 (F) Alloy)}

Figure 4 shows typical microstructures on the forged and subsequent heat treated microstructures (through the processing route of Fig. 1(b)) of the Ti-17(F) alloy. Initial microstructure on the as-received Ti-17 alloy is as shown
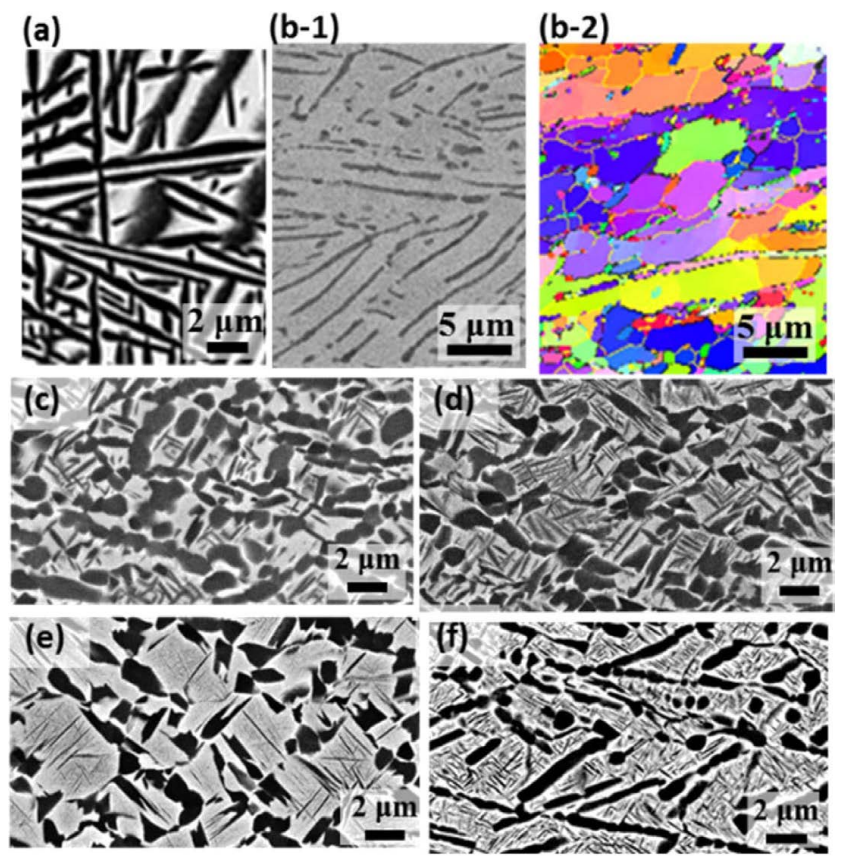

Fig. 4. Typical microstructures of the Ti-17(F) alloy: (a) asreceived specimen, (b-1,2) as-forged specimen at $850^{\circ} \mathrm{C}$ and $10^{-2} \mathrm{~s}^{-1}$ ((b-1) SEM image and (b-2) EBSD-orientation image), SEM images of $(\mathrm{c}-\mathrm{f})$ the heat treated specimens after forging. Here, the cooling rates are (c) $0.15^{\circ} \mathrm{C} / \mathrm{s}$ and (e) $0.71^{\circ} \mathrm{C} / \mathrm{s}$, respectively (processed from Fig. 1(b-1)). (d) Aged specimen at $650^{\circ} \mathrm{C}$ for $1 \mathrm{~h}$ (processed from Fig. 1(b-5)), (f) Aged specimen after two step aging at $800^{\circ} \mathrm{C}$ (for $1 \mathrm{~h}$ ) and $600^{\circ} \mathrm{C}$ (for $1 \mathrm{~h}$ ) (processed from Fig. 1(b-5)). (Online version in color.)

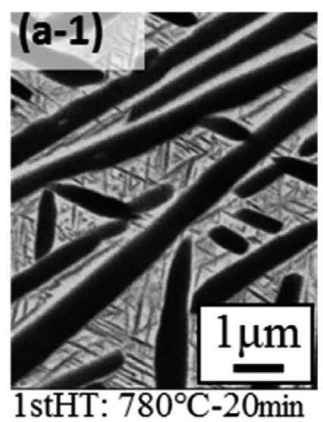

2nd HT: $550^{\circ} \mathrm{C}-1 \mathrm{hr}$

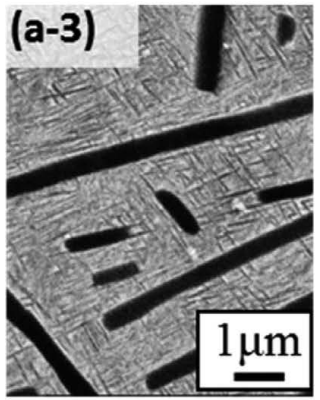

1stHT: $850^{\circ} \mathrm{C}-20 \mathrm{~min}$

2nd HT: $550^{\circ} \mathrm{C}-1 \mathrm{hr}$
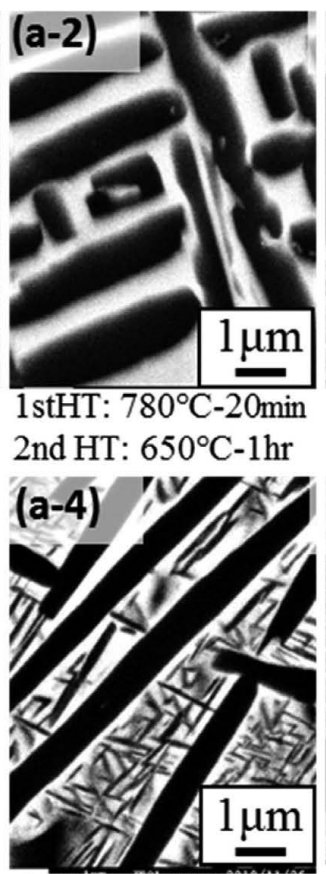

1stHT: $850^{\circ} \mathrm{C}-20 \mathrm{~min}$ 2nd HT: $650^{\circ} \mathrm{C}-1 \mathrm{hr}$

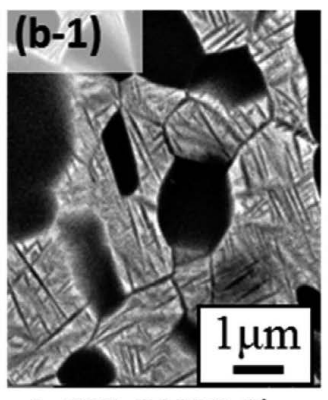

1stHT: $800^{\circ} \mathrm{C}-3 \mathrm{~h}$

2nd HT: $550^{\circ} \mathrm{C}-1 \mathrm{hr}$
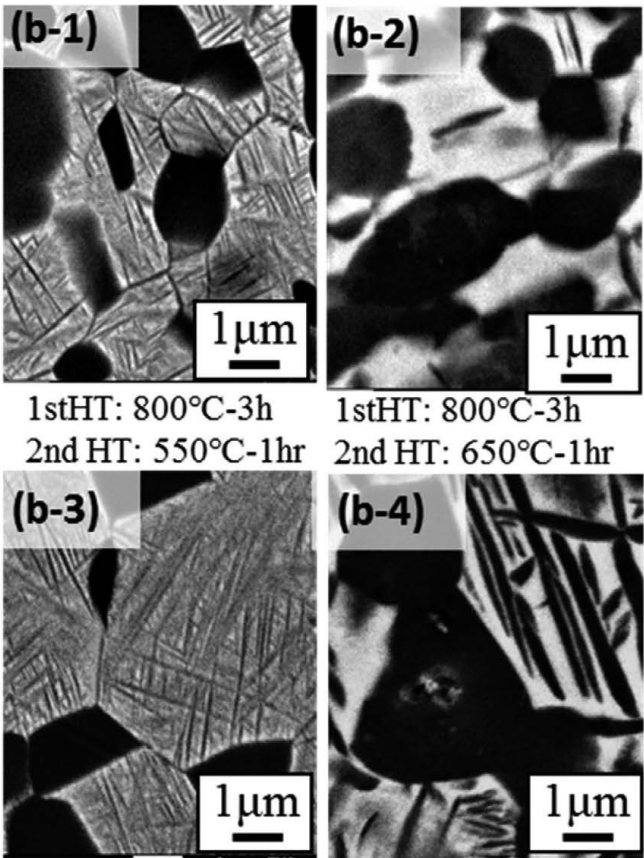

1stHT: $850^{\circ} \mathrm{C}-3 \mathrm{~h}$

2nd HT: $550^{\circ} \mathrm{C}-1 \mathrm{hr}$ 2nd HT: $650^{\circ} \mathrm{C}-1 \mathrm{hr}$

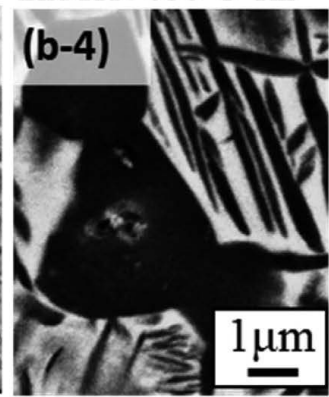

1stHT: $850^{\circ} \mathrm{C}-3 \mathrm{~h}$

2nd HT: $650^{\circ} \mathrm{C}-1 \mathrm{hr}$

Fig. 3. Typical low-temperature aging microstructures of the Ti-17(A) alloy: (a-1-4) the bi-lamellar morphology (heat treated from the as-received specimen) and (b-1-4) the bimodal morphology (heat treated from the $850 \mathrm{HR}$ specimen). Herein, heat treatment conditions for the 1st HT and 2nd HT (as illustrated in Fig. 1(a)) are represented. 
in Fig. 4(a), revealing the lamellar $(\alpha+\beta)$ morphology. After forging at $850^{\circ} \mathrm{C}$ and $10^{-2} \mathrm{~s}^{-1}$ and a height reduction of $50 \%$ followed by quenching into oil, a kinking of $\alpha$-lamellae and equiaxed $\beta$ subgrains are observed from Figs. 4(b-1), 4(b-2). Controlling of a cooling rate after the forging results in the different morphology: a fast cooling at a rate of $0.71^{\circ} \mathrm{C} / \mathrm{s}$ leads to the formation of fine secondary $\alpha$ lamellae as a continuous precipitation manner (Fig. 4(e)), while a slow cooling at a rate of $0.15^{\circ} \mathrm{C} / \mathrm{s}$ enhances the diffusion process and coarsening of the secondary $\alpha$ lamellae (Fig. 4(c)). From Fig. 4(d), the low temperature aging at $650^{\circ} \mathrm{C}$ and a holding time for $1 \mathrm{~h}$ can control the size of secondary $\alpha$ lamellae. Additionally, the high-temperature $\left(800^{\circ} \mathrm{C}\right)$ and low-temperature $\left(600^{\circ} \mathrm{C}\right)$ two step aging is found to exhibit the microstructure composed of a primary $\alpha$-lamellae and a fine secondary $\alpha$ lamellae (so called as bi-lamellar $(\alpha+\beta)$ microstructure) (Fig. 4(f)). Two-step aging process can control the fraction of primary $\alpha$ phase and the size of secondary $\alpha$-lamellae. Thus, various kinds of bimodal microstructures and $(\alpha+\beta)$ bi-lamellar microstructures are obtained from the process combining the forging, controlling the cooling rate and subsequent aging process.

Regarding the precipitation behavior of the secondary $\alpha$ phase from supersaturated $\beta$, Fig. 5 shows (a)(b-1) the TEM bright field images and (b-2) the EBSD orientation image shown by all Euler angles map (the color phase corresponds to the $\alpha$ phase and the black phase does the $\beta$ phase). Here, Fig. 5 shows the microstructures of the Ti-17 (F) alloy forged at $850^{\circ} \mathrm{C}$ followed by cooling at a rate of $0.71^{\circ} \mathrm{C} / \mathrm{s}$ (Fig. $5(\mathrm{a})$ ) and subsequent low temperature aging at $650^{\circ} \mathrm{C}$ (Figs. $5(\mathrm{~b}-1), 5(\mathrm{~b}-2))$. After a rapid cooling at a rate of $0.71^{\circ} \mathrm{C} / \mathrm{s}$, the aggregate of fine acicular secondary $\alpha$-precipitates are observed. Herein, Fig. 5(a) reveals a significant amount of the fringe-diffraction contrast in the aggregates of the $\alpha$ precipitates, which is indicative of the elastic lattice distortion and an increased dislocation density. On the other hand, the aging process at $650^{\circ} \mathrm{C}$ is found to lead to an weakening of the fringe-diffraction contrast (which is indicative of anni-

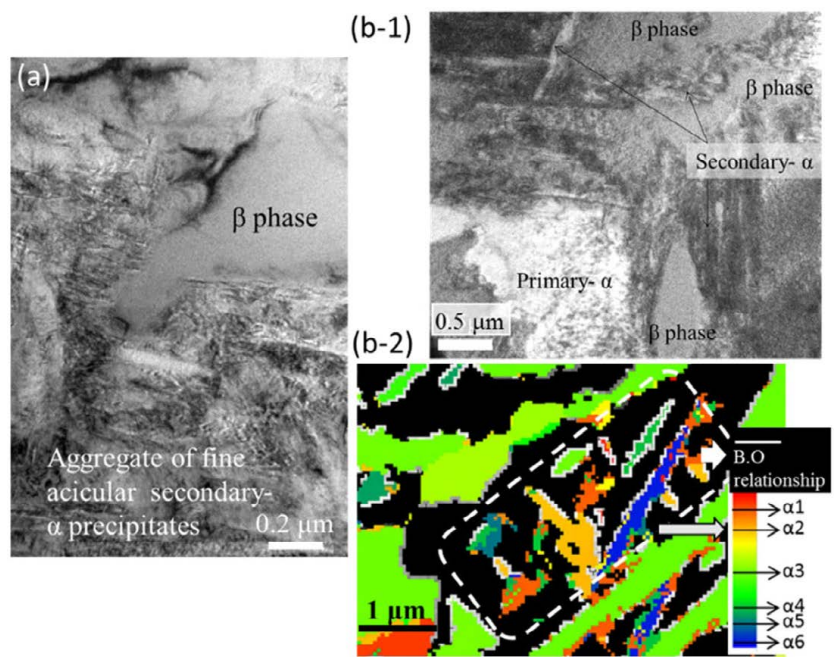

Fig. 5. (a)(b-1) Bright field TEM images and (b-2) EBSD-all Euler map (showing the 6 variants of $\alpha$ and B.O orientation relationship shown by a white line) of the Ti-17(F) alloy. (a) as-forged specimen at a cooling rate of $0.71^{\circ} \mathrm{C} / \mathrm{s}$ and $(\mathrm{b}-1,2)$ subsequent aging specimen that aged at $650^{\circ} \mathrm{C}$ for $1 \mathrm{~h}$. (Online version in color.) hilation of dislocations accompanied by recovery process) and a coarsening of the size of secondary $\alpha$-precipitates as shown in Fig. 5(b-1). According to the EBSD maps from Fig. 5(b-2), we can observe the bimodal morphology and various orientations of the secondary $\alpha$ precipitates in the region that is surrounded by white dotted line. Here, white bold-line drawn at interfaces between the $\beta$ phase and the secondary $\alpha$ precipitates show the interface obeying the well known Burgers orientation (B.O) relationship of (0001) $\alpha / /$ $\{110\} \beta$ and $<11 \overline{2} 0>\alpha / /<111>\beta{ }^{13)}$ From Fig. 5(b-2), it can be observed from the region of the secondary $\alpha$ precipitates that 6 variants (among twelve equivalent variants having the B.O relationship) are formed by obeying the B.O relationship.

On the precipitation of the secondary $\alpha$ phase in the Ti-17 alloy, Teixeira et al. reported that the $\alpha_{\mathrm{WI}}$ (Widmanstätten Intragranular) precipitates formed at temperature range between $550^{\circ} \mathrm{C}$ to $700^{\circ} \mathrm{C}$ under isothermal heat treatment from supersaturated $\beta ;^{14,15)}$ the $\alpha_{\mathrm{WI}}$ precipitates (formed by isothermal treatment) revealed the typical "basket weave morphology" having the triangular arrangements of individual variants dominate, which is formed under selfaccommodated variant distributions governed by elastic interactions. ${ }^{16,17)}$ As abovementioned from the present work, a high cooling rate at $0.71^{\circ} \mathrm{C} / \mathrm{s}$ seems to result in multivariant formation of the secondary $\alpha$, followed by variant selection and growing into 6 variants by subsequent isothermal heat treatment (as shown in Fig. 5). Hence, it can be interestingly speculated from the present work that the kinds of variant and its selection of the $\alpha_{\mathrm{WI}}$-precipitation from supersaturated $\beta$ are different depending on the processing conditions of cooling rate and isothermal treatment process.

\subsection{Mechanical Properties of the Ti-17(A) Alloy}

In order to clarify the effects of morphology, sizes (grain size, precipitation size, inter-lamellar size), the $\alpha / \beta$ fraction, and the presence of the fine secondary $\alpha$ plates on the strength and ductility balance quantitatively, the relationship between microstructural factors and tensile properties of the Ti-17(A) alloy were systematically evaluated in this section.

\subsubsection{Plastic Flow Behavior and Strength-ductility Bal- ance}

Figure 6(a) shows the plastic flow behaviors of the Ti17(A) alloys with typical various microstructures of three morphology (the equiaxed, the bimodal and the lamellar typed morphology with and without secondary $\alpha$ precipitates). The heat treatment conditions of the Ti-17(A) alloys are also represented in Fig. 6(a). A marked increasing in flow stress value and a slight decreasing in ductility are clearly observed accompanied by the formation of the secondary $\alpha$ precipitates. Additionally, a higher work hardening rate just after a yielding point is also noted for the microstructures with secondary $\alpha$ precipitates, implying that dislocation-interaction with the precipitates are enhanced due to the secondary $\alpha$ precipitates. Compared to the flow behaviors among these three morphology, a similar strength level is observed between the equiaxed- and the lamellar- microstructure, and a higher elongation to fracture is exhibited in the equiaxed microstructure than the lamellar microstructure. To summarize, Fig. 6(b) shows the ultimate 
(a)

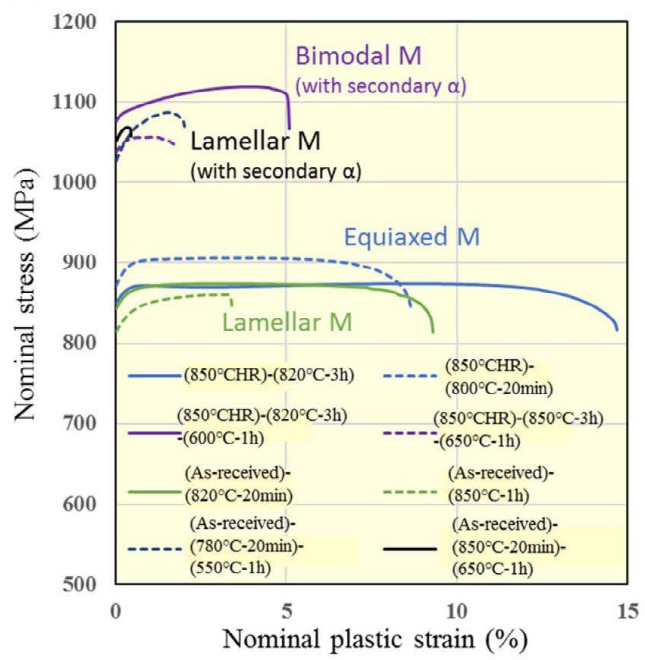

(b)

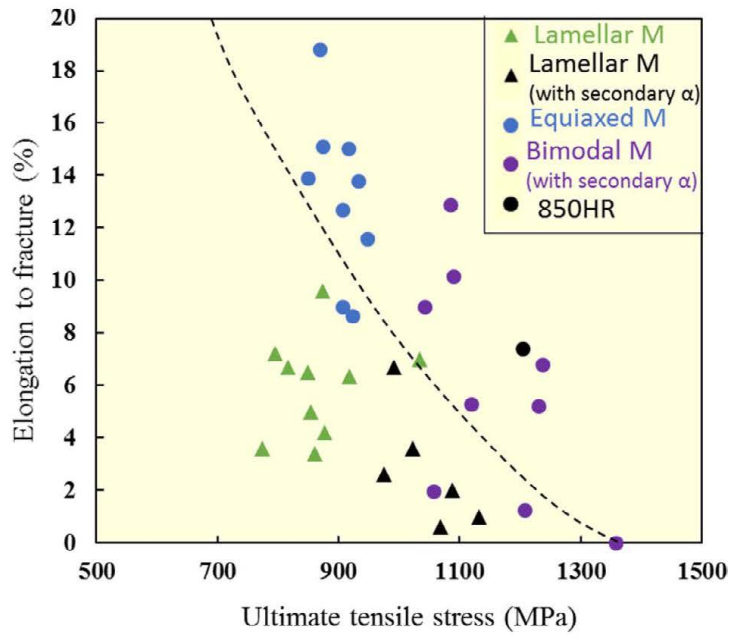

Fig. 6. (a) Nominal stress and nominal plastic strain curves of the Ti-17(A) alloys having various microstructures. (b) Relationship between ultimate tensile stress and ductility (elongation to fracture) of the Ti-17(A) alloy (for all microstructures examined in this work). (Online version in color.)

tensile stress and ductility (elongation to fracture) balance of the Ti-17(A) alloys, we can observe the trade-off relationship which is often called as a "banana curve" due to its shape. The dotted line in Fig. 6(b) indicates the average line for the all experimental values. From this relationship, we can clearly classify the tendency of strength-ductility relation depending on the morphology; a low-strength and small-ductility is obtained in the lamellar microstructure and a low-strength and large-ductility is done in the equiaxed microstructure. Among the all morphology, it can be found that the bimodal microstructure (consisting of an equiaxed $\alpha$ grain and secondary $\alpha$ precipitates) exhibits higher strength and larger ductility. Thus, as similar to the other Ti alloys, ${ }^{1)}$ the bimodal typed structure is beneficial for the enhanced balance of strength and ductility in the Ti-17 alloys. Indeed, the recent work of the Ti-17 alloy by $\mathrm{Xu}$ et $a{ }^{10)}{ }^{10)}$ also reported that an increasing fraction of $\alpha$-globularization phase led to an increasing of strength, plastic elongation and area of reduction simultaneously. On the other hand, with respect to fracture toughness in the $(\alpha+\beta)$-Ti alloys, it is well known that acicular- or lamellar morphology is beneficial for the improved toughness although equiaxed or bimodal morphology is effective for improving the ductility. ${ }^{18)}$ Fracture toughness is an important property as well as strength and ductility, therefore, the effect of microstructural factor on fracture toughness is herein also commented. The mechanism of the improved toughness in acicular- or lamellar morphology is considered to be thanks to "microcrack induced toughening mechanism" in which frequent microcrack formation contributes to relaxation of stress concentration at the crack tip and an increasing the tortuosity of the crack path. ${ }^{19,20)}$ Indeed, the recent work on the Ti-17 alloy by Liang et al. pointed out that the lamellar morphology showed a superior fracture toughness over the bimodal morphology. ${ }^{21)}$

\subsubsection{Microstructural Effect on Ductility and Necking}

In order to identify the effect of $\alpha$ precipitates of the coarse primary $\alpha$ and the fine secondary $\alpha$ on the ductility, Fig. 7(a) shows the effect of the ratio between the fraction of secondary- and primary $\alpha$ precipitates on the elongation to fracture for the lamellar and the bimodal morphology. The formation of the secondary $\alpha$ precipitates is found to lead to a marked decreasing of ductility. For the bimodal morphology, we can note that higher ductility is kept than the lamellar morphology owing to the geometrical effect in microstructures (that suppresses the inhomogeneous deformation mode).

It is well recognized that higher tensile ductility is obtained in equiaxed morphology than lamellar morphology. ${ }^{1)}$ The tensile ductility of $(\alpha+\beta)$-Ti alloys is mainly dominated by two factors of crack nucleation resistance and crack propagation resistance, and the former is the more dominating factor. So, crack nucleation specifically at $\alpha / \beta$ interface is occurred easier in the lamellar morphology. In the near $\beta$ typed $(\alpha+\beta)$ and the $\beta$ typed alloys, the strength-ductility balance is strongly dependent on the $\beta$ grain size and the kind and morphology of precipitates. ${ }^{18)}$ In this regard, Furuhara et al. indeed pointed out that a uniform distribution of the $\alpha$ precipitates with multi-variants contributed to the enhanced ductility with keeping high strength. ${ }^{22)}$ Herein, they mentioned that the improvement of ductility (for increasing the local elongation) was achieved by the frequent deflection of cracks due to $\alpha$ precipitates with multi-oriented variants. Thus, we can confirm that the $\alpha$ precipitates have an influence on not only the strength but also the ductility.

Next, in order to clarify the correlation between the total elongation and the necking behavior, Fig. 7(b) summarizes the relationship between the elongation to fracture and the reduction of area after tensile test of the Ti-17(A) alloys with various microstructures. Except for the Ti-17(A) alloy with an equiaxed microstructure, there is a good correlation between the elongation and the reduction of area. From Fig. 7(b), it can be interestingly noted for the equiaxed microstructures that there are strong variations on the reduction of area at the higher elongation region. The variations observed in the equiaxed microstructure are supposed to be due to the effect of grain size; a large necking region is appeared with decreasing the grain size of $\alpha$ phase and $\beta$ phase, being 
(a)

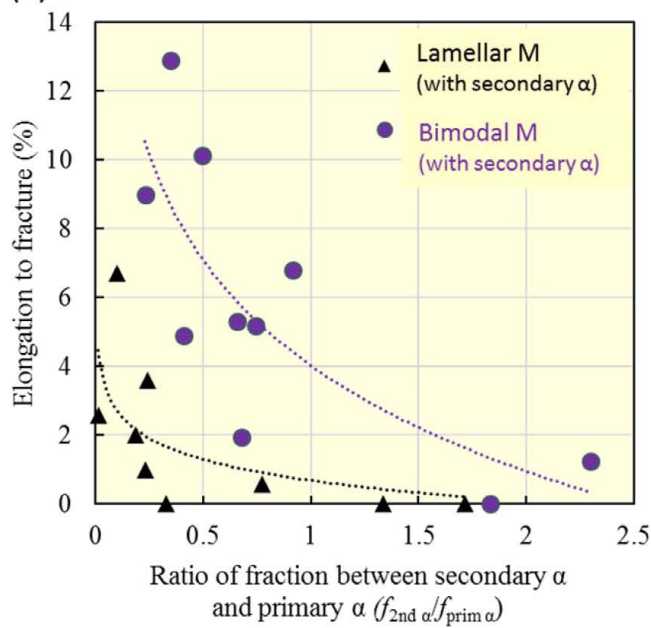

(b)

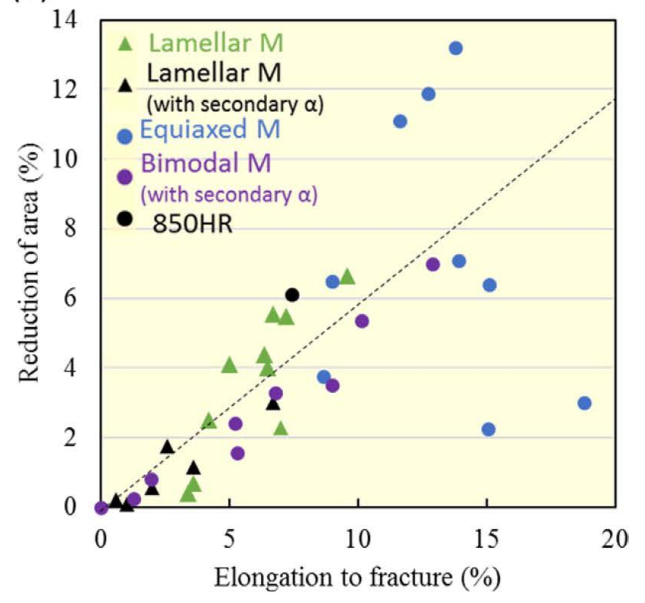

Fig. 7. (a) The effect of ratio of fraction between secondary $\alpha$ and primary $\alpha$ on the elongation to fracture of the Ti17(A) alloy for the bi-lamellar and the bimodal microstructures. (b) Relationship between the elongation to fracture and the reduction of area of the Ti-17(A) alloy for all microstructures. (Online version in color.)

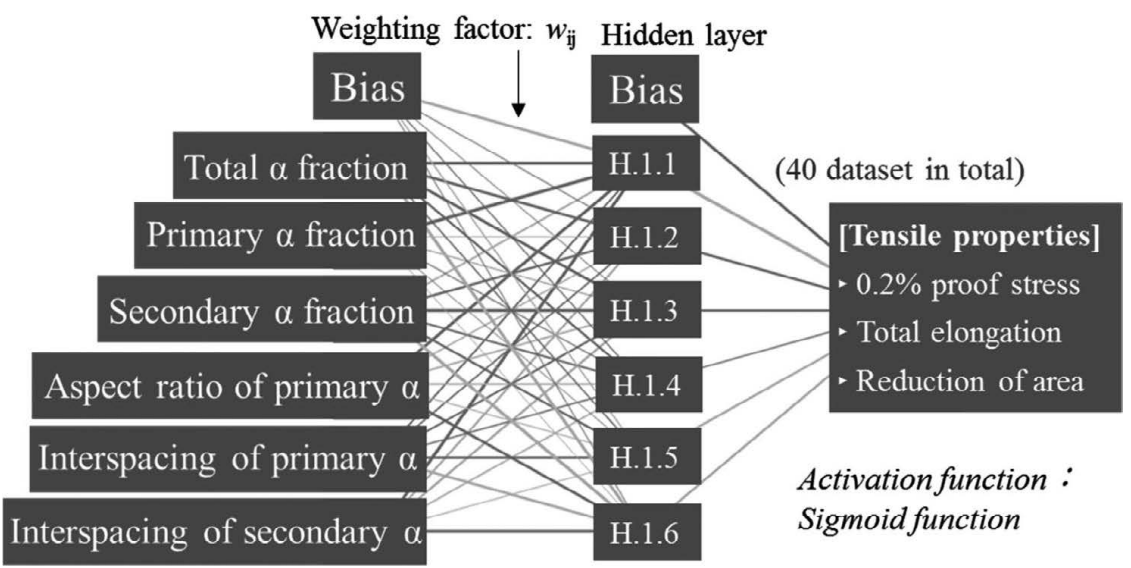

Fig. 8. Architecture of the neural network regression process in this work (for linking between the microstructural factor and tensile properties).

indicative of an occurrence of inhomogeneous deformation. In other word, the result from Fig. 7(b) interestingly points out that there is no apparent influence of the grain (or precipitate) sizes on necking behavior for the lamellar and bimodal morphology. Thus, we can confirm that the ductility as well as the strength is strongly affected by the morphology, the $\alpha$ precipitates and the fraction ratio of primary $\alpha$ and secondary $\alpha$. Hereafter, the correlation among the microstructural factors and tensile properties of strength, elongation and reduction of area will be quantitatively analyzed thanks to a machine learning approach.

\subsubsection{Microstructural Effect on Mechanical Properties Estimated by a Machine Learning Approach}

This work estimates the microstructural factor affecting the tensile properties quantitatively by means of a machine learning approach. Among the various machine learning algorithms, the neural network (NN) is suitable for simulations of correlations which are hard to describe or cannot be accurately predicted by physical models. ${ }^{23)}$ The NN modeling is essentially an operation linking input to output data, by using a particular set of non-linear basis functions. Figure 8 illustrates the schematic structure of $\mathrm{NN}$ in this work: 1 hidden layers and 7 neurons including 1 bias. There are 7 input factors of 6 microstructural factors and 1 bias, and the outputs correspond to the tensile properties $(0.2 \%$ proof stress, total elongation (elongation to fracture) and reduction of area). Herein, a sigmoid function $\left[1 /\left(1+e^{-x}\right)\right]$ is applied as the activation function, and the input and output variables $(Z)$ are normalized to be $Z_{\mathrm{i}}$ as following Eq. (1):

$$
Z_{i}=0.1+0.8 \times\left(\frac{Z-Z_{\text {min }}}{Z_{\text {max }}-Z_{\text {min }}}\right)
$$

Figure 9 summarizes the relationship between the NN results and the experimental results of (a) $0.2 \%$ proof stress, (b) total elongation of the Ti-17(A) alloys with various microstructures. Coefficient of determination, $r^{2}$ is also represented in Fig. 9. We can observe a good correlation between the NN results and the experimental results for both tensile properties, indicating that $\mathrm{NN}$ is successfully carried out for regression analysis precisely. In addition, a good correlation between the NN results and the experimental results has been also confirmed on the reduction of area. Figure 10 summarizes the fraction (in \%) showing sensitivity of the importance affecting the tensile properties $(0.2 \%$ proof stress, total elongation and reduction of area). This fraction is estimated from a measure how much the predicted value's error increases when the variables are excluded 
(a)

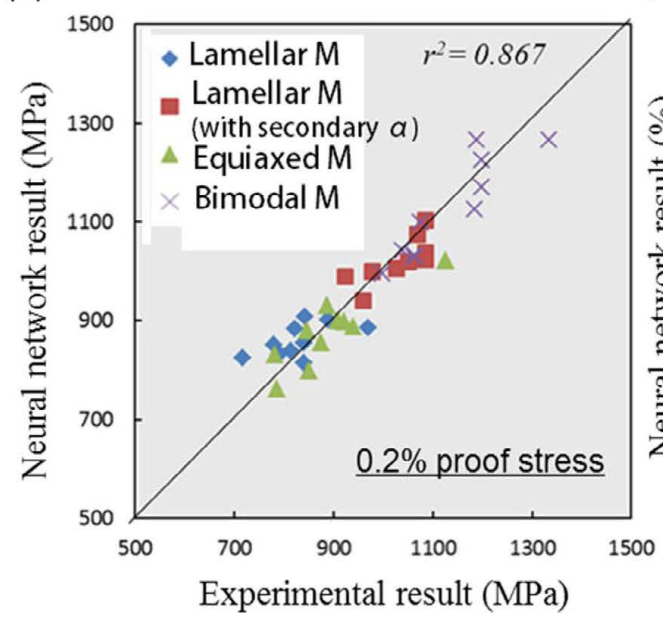

(b)

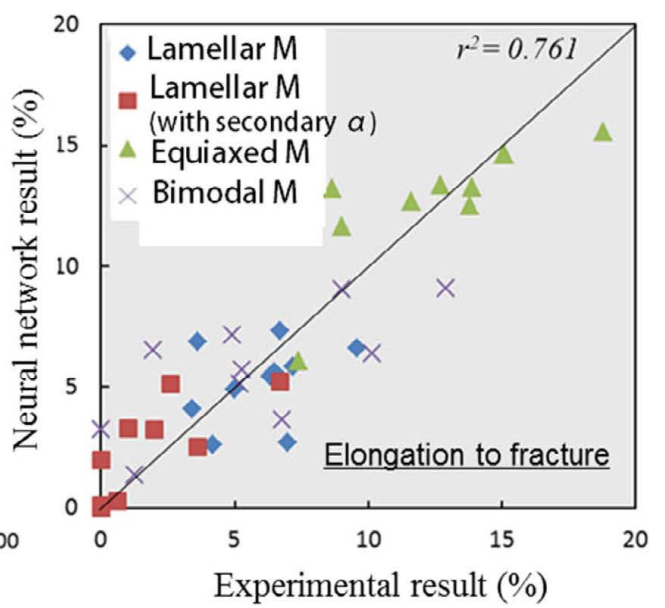

Fig. 9. Correlation between the experimental result and the NN result of (a) $0.2 \%$ proof stress and (b) elongation to fracture of the Ti-17(A) alloy for all microstructures. (Online version in color.)

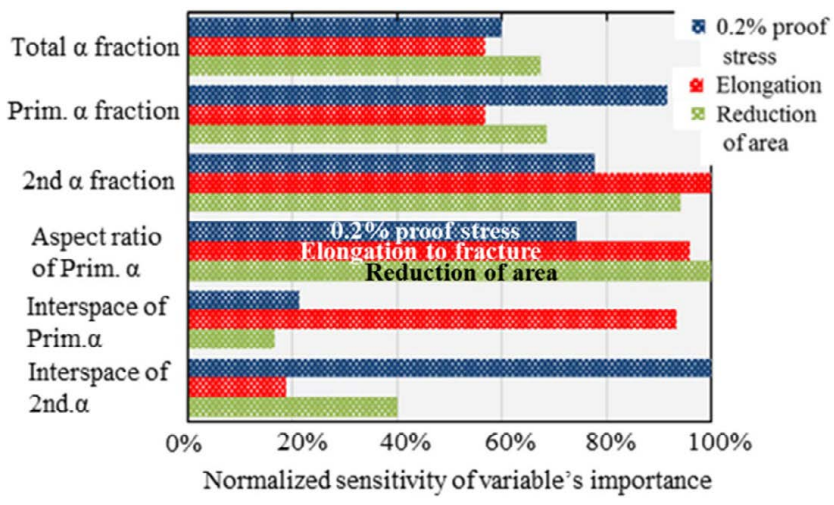

Fig. 10. Sensitivity (expressed in \%) of the predictor variables' importance (importance of each microstructural factor) on the tensile properties according to $\mathrm{NN}$ analysis. (Online version in color.)

from the model one at a time. Here, instead of actually excluding variables, they are fixed at a constant value of an average value. Therefore, the determined fraction from Fig. 10 means the importance that has an influence on tensile properties. From Fig. 10, we can see the quantitative degree that affects the tensile properties. Here, we can interestingly note that the microstructural factor affecting strongly is different among the tensile properties $(0.2 \%$ proof stress, total elongation and reduction of area); the strength is strongly affected by the interspace of secondary $\alpha$ phase and the fraction of primary $\alpha$ phase, on the other hand, the ductility (elongation and reduction of area) is strongly affected by the fraction of secondary $\alpha$ phase and the aspect ratio of primary $\alpha$ phase. On the ductility, as I stated for the result from Fig. 7 , the elongation is indeed strongly affected by the fraction of secondary $\alpha$ and the morphology, which is in good agreement with the result from the machine learning (Fig. 10). Moreover, for the microstructural factor of interspace of primary $\alpha$ phase, we can note a low sensitivity for the reduction of area while a high sensitivity is observed for the elongation. This is mainly attributable to the influence of morphological factor. That is, as the present author mentioned from Fig. 7(b), there was large variations in the relationship of the elongation and reduction of area specifically for the equiaxed morphology. We didn't consider the morphological factor on the estimation of linking (for the sensitivity) as shown in Fig. 8. Hereafter in next stage, we will try to link them according to a machine learning approach with considering the morphological factor for clarifying the activating mode in ductility in detail. In addition, as I discussed on the strength in detail as following section, the strengthening mechanism of the Ti-17 alloy is deduced to be mainly dominated by the rule-of-mixtures for the coarse primary $\alpha$ phase and the precipitation hardening by the fine secondary $\alpha$ phase, which is also in good agreement with the result from machine learning.

Thus, the machine learning approach (according to the neural network algorithm) is found to reliably link between the microstructural factor and tensile properties, thereby, providing us the information on their correlation quantitatively.

\subsection{Hardening Mechanism Originated from $\alpha$ Precipi- tation of the Ti-17(F) Alloy}

As abovementioned according to the experimental and machine learning approaches, strengthening (hardening) in the Ti-17 alloys is found to be strongly affected by the $\alpha$ precipitates (specifically influenced by the secondary $\alpha$ ) which is associated with the precipitation hardening. Hereafter, we shall discuss the strengthening mode by the $\alpha$ precipitates more in detail. In this section, we mainly report the results from the Ti-17(F) alloy because there are many kinds of microstructures with changing the $\alpha$ precipitation behavior prepared in the Ti-17(F) alloy. A good correlation between the strength and the Vickers hardness has been experimentally confirmed for the Ti-17(A) alloys, therefore, the precipitation hardening mechanism is hereafter discussed with the result of Vickers hardness. Figure 11(a-1) shows the Vickers hardness of the Ti-17(F) alloy as a function of the inverse of inter-lamellar spacing of the primary $\alpha$ and secondary $\alpha$, respectively. It is well recognized that precipitation hardening according to the Orowan law is dominated by the inverse of inter-precipitate spacing. Interlamellar spacing; $\lambda$ was calculated as following Eq. (2). ${ }^{24,25)}$

$$
\lambda=1.25\left(\pi \overline{w_{L}^{3}} / 6 f \overline{w_{L}}\right)^{1 / 2}-\left(\pi \overline{w_{L}^{2}} / 4 \overline{w_{L}}\right) \ldots
$$



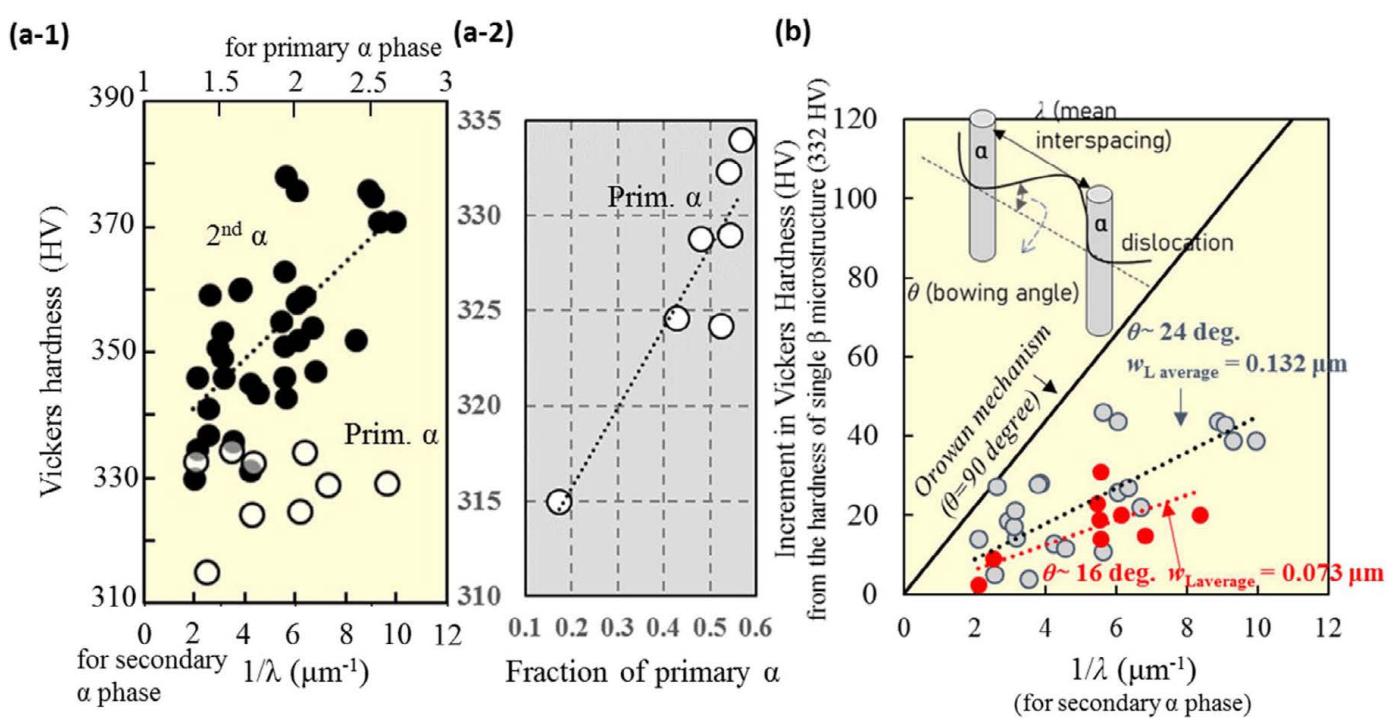

Fig. 11. Relation between inter lamellar spacing $(\lambda)$ and (a-1) Vickers hardness and (b) increment of Vickers hardness from the hardness $(332 \mathrm{HV})$ for the single $\beta$ microstructure ((a-1) the results for the primary $\alpha$ phase and the secondary $\alpha$ phase, (b) the result of secondary $\alpha$ phase with subdivision by the hierarchical clustering of Ward's method). (a-2) The dependence of fraction of primary $\alpha$ phase on Vickers hardness. (Online version in color.)

where $w_{\mathrm{L}}$ is width of the $\alpha$-lamellae and $\overline{w_{L}}, \overline{w_{L}^{2}}$ and $\overline{w_{L}^{3}}$ denote the average of $w_{L}, w_{L}^{2}, w_{L}^{3}$, respectively. The $f$ is the volume fraction of $\alpha$ precipitates (of the primary $\alpha$ and secondary $\alpha$, respectively).

From Fig. 11(a-1), we can find some correlation for the secondary $\alpha$ precipitates, on the other hand, there is no correlation for the primary $\alpha$ precipitates. This result interestingly points out that the primary $\alpha$ precipitates does not act as an Orowan strengthening mechanism, instead, it acts as only the strengthening according to the rule-of-mixtures. In this regard, the machine learning also judged a small degree of importance for the interspacing of primary $\alpha$ phase on the strength as shown in Fig. 10. For proving it, Fig. 11(a-2) shows the relationship between fraction of primary $\alpha$ phase (here, two results for the specimens having large strains are removed so as to eliminute the effect of strain hardening) and Vickers hardness of the Ti-17(A) alloys without formation of secondary $\alpha$ phase. We can observe from Fig. 11(a-2) the linear relationship clearly, being indicative of the rule-of-mixtures dominantly occurred for the strengthening by the primary $\alpha$ phase. So, the precipitation hardening is hereafter discussed only for the effect of the secondary $\alpha$ phase. Figure 11(b) shows the relationship between the inverse of inter-lamellar spacing of secondary $\alpha$ phase and the increment of hardness from the Vickers hardness of the Ti-17(F) alloy composed of a single $\beta$ phase (332 HV). In order to roughly classify the microstructural feature of the Ti-17(F) alloys, a hierarchical clustering based on the Ward's method ${ }^{26)}$ was carried out for the dataset of four variables of a fraction of primary $\alpha$ phase, a fraction of secondary $\alpha$ phase, a width of primary $\alpha$ phase and a width of secondary $\alpha$ phase, followed by classifying into two groups corresponding to the red plots and blue plots as shown in Fig. 11(b). As a main feature of this classification, a large width of secondary $\alpha$ phase tends to be revealed for the blue plots, while a small width of secondary $\alpha$ phase is obtained for the red plots.

A dispersion of second phase particles or precipitates within the matrix is very effective for strengthening the alloy, since the moving dislocations are pinned by these particles or precipitates. It is well recognized as the dispersion strengthening or the precipitation strengthening. Regarding the general constitutive formula showing the increment of stress $(\Delta \sigma)$ by precipitation strengthening is expressed by the following Eq. (3).

$$
\Delta \sigma=(M \mu b / \lambda) \sin \theta
$$

where $b$ is magnitude of the Burgers vector of matrix $\beta$ $\left(=2.86 \times 10^{-10} \mathrm{~m}\right), \mu$ is the shear modulus of $\beta(=44 \mathrm{GPa})$, and $M$ is Taylor factor $(=2.9)$. The $\theta$ from Eq. (3) is the bowing angle between precipitate. If the $\theta$ reaches at $\pi / 2$ for bowing of the moving dislocation, it indicates the activation of the Orowan strengthening mode accompanied by dislocations by-pass process. On the other hand, the bowing angle of $\theta$ should be taken into account for the increment of strengthening $(\Delta \sigma)$ if the moving dislocation passes through the precipitates before the $\theta$ reaches $\pi / 2$. This strengthening mode affected by the $\theta$ is cutting ${ }^{27)}$ or climbing mechanism. ${ }^{28)}$ From Fig. 11(b), the degree of strengthening is expressed in an increment of Vickers hardness from the single $\beta$ microstructure since the proof stress can be converted from the Vickers-hardness according to Hill's law as following Eq. (4). ${ }^{29)}$

$$
\text { Proof stress }(\mathrm{MPa}) \cong 9.8 \times(\text { Vickers hardness }(\mathrm{HV})) / 3
$$

From Fig. 11(b), the straight lines denote the theoretical value of precipitation strengthening obtained by the Eq. (3) using various $\theta$ : the black bold straight line corresponds to the estimated stress by Orowan mechanism $\left(\theta=90^{\circ}\right)$. We can observe the large gap between the experimental values and the estimated hardness according to the Orowan strengthening $\left(\theta=90^{\circ}\right)$, implying that the cutting mode is dominant as a main hardening (strengthening) mechanism for the secondary $\alpha$ precipitates in the present alloy. Additionally, we can observe the bowing angle increases 
with increasing the width of secondary $\alpha$ precipitate from $0.073 \mu \mathrm{m}$ to $0.132 \mu \mathrm{m}$ (in average value), and we can estimate the critical width of $\alpha$ precipitate for achieving the Orowan mechanism optimally at and around $0.31 \mu \mathrm{m}$. This result indeed indicates the possibility for the further enhanced strength by controlling the $\alpha$-precipitate behavior.

Regarding the critical size for the spherical precipitate for changing the hardening mode from the cutting mechanism to the Orowan mechanism in the metallic alloys, in the $\mathrm{Cu}-\mathrm{Cr}$ alloys, the Orowan mechanism shall be the determining interaction when the $\mathrm{Cr}$ precipitates grow to approximately $3.4 \times 10^{-2} \mu \mathrm{m}$. $^{30)}$ For the $\mathrm{Fe}-\mathrm{Cu}$ alloys, the critical size of $\mathrm{Cu}$ precipitate was reported to be $7.0 \times 10^{-2}$ $\mu \mathrm{m} .{ }^{24)} \mathrm{In}$ addition, its critical size for the Ni-based alloy (Ni-26 wt.\%Co-13wt.\%Cr alloy system) was reported to be $(5.0-6.0) \times 10^{-2} \mu \mathrm{m} .^{31)}$ Thus, the critical size of precipitate in metallic alloys for transition from the cutting to the Orowan mechanism seems to be ranged below $0.1 \mu \mathrm{m}$. On the other hand, regarding the Ti alloy (for the Ti-3Al-8V$6 \mathrm{Cr}-4 \mathrm{Mo}-4 \mathrm{Zr}$ alloy), ${ }^{32)}$ the $\alpha$ precipitates with the spherical diameter of $0.16 \mu \mathrm{m}$ does not act as the Orowan mechanism. Herein, Rhodes and Paton have pointed out that coherency strains arising from precipitate misfit contributed to significant strengthening. ${ }^{32)}$ As stated above, a critical width of the secondary $\alpha$ precipitate for the transition from the cutting to the Orowan mechanism is estimated to be around $0.31 \mu \mathrm{m}$ in this work. This larger estimated size compared to the critical sizes for the other metallic alloys as above mentioned is supposed to be attributable to the difference in the precipitate morphology. That is, a fine lamellar (or acicular) morphology observed in the present Ti-17 alloys is supposed to act as a barrier for dislocation motion owing to the difficulty to climb over the precipitates more than the spherical precipitates. Indeed, a maximum strength value is presented at a width of lamellar $\alpha$ of $0.2 \mu \mathrm{m}$ on the strengthening of two phases Ti alloy of the Ti-30Zr-5Al-3V alloy with a basket-weave microstructure. ${ }^{33)}$

To summarize, this work clarified the microstructural factor affecting the strength and ductility in the Ti-17 alloys having various kinds of microstructures quantitatively in terms of both approaches of the experiment and the machine learning: the strength (or hardness) was mainly affected by the fraction of coarse primary $\alpha$ phase and inter-lamellar spacing of the secondary $\alpha$ precipitates (which is dominated by the cutting mechanism), on the other hand, the ductility was mainly affected by the fraction of secondary $\alpha$ phase, the interspace of primary $\alpha$ and the aspect ratio of primary $\alpha$ phase. Here, we can note that the microstructural factor that affects the mechanical properties is different between the strength and the ductility. Thus, the analyzing in combination with an experimental work and a machine learning is found to successfully provide a quantitative estimation of the dominant modes of mechanical properties correlating to the microstructural factors in the Ti-17 alloy. Thanks to it, we will aim at microstructural controlling of the Ti-17 alloy experimentally for achieving the further enhancement of the strength and ductility balance in the next stage.

\section{Summary}

The present study aims at the quantitative understand- ing on correlation between microstructures and mechanical properties of a Ti-17 alloy in terms of an experimental approach and a machine learning approach. Two types of Ti-17 alloy specimens are prepared: the Ti-17(A) alloy produced by hot rolling and subsequent heat treatments and the Ti-17(F) alloy produced by isothermal forging and subsequent heat treatments. The obtained results are as follows.

(1) Four $(\alpha+\beta)$ microstructures of equiaxed- , lamellar, bimodal and bi-lamellar (with fine secondary $\alpha$ lamellae) morphology with changing the grain or lamellae sizes and the $\alpha / \beta$ ratio are prepared in the Ti-17(A) alloy. On the Ti$17(\mathrm{~F})$ alloys, a fast cooling at a rate of $0.71^{\circ} \mathrm{C} / \mathrm{s}$ after forging results in the formation of fine secondary $\alpha$ lamellae with multi-variants as a continuous precipitation manner, and a slow cooling at a rate of $0.15^{\circ} \mathrm{C} / \mathrm{s}$ enhances the diffusion process and coarsening of the $\alpha$ lamellae. Two step aging after forging exhibits the bi-lamellar microstructure, and a controlling of the two-step aging process (with changing aging temperatures) can vary the fraction of primary $\alpha$ phase and the size of secondary $\alpha$-lamellae.

(2) Among the various morphology in the Ti-17(A) alloy, high strength is obtained in the microstructure with fine secondary $\alpha$ lamellae (for the bimodal and the bilamellar microstructures). Additionally, a good property in the strength and ductility balance is exhibited in a bimodal microstructure. On the strengthening (hardening) mode affected by the $\alpha$ phase, the primary $\alpha$ phase (an equiaxed grain or a lamellae) acts as only the strengthening according to the rule-of-mixtures, on the other hand, the fine secondary $\alpha$ lamellae (precipitated from supersaturated $\beta$ phase) acts as the precipitation strengthening dominated by cutting mechanism. While, the ductility is experimentally found to be strongly affected by the difference in morphology and the formation of secondary lamellar $\alpha$ precipitates; the higher ductility is obtained in an equiaxed grained morphology and in the microstructure with a decreasing fraction of secondary $\alpha$ precipitates.

(3) With respect to the effect of microstructures on strength and ductility analyzed by a machine learning approach, neural network and clustering (the Ward's method) algorithms successfully predict the linking between the microstructural factors and mechanical properties. Here, we clarified quantitatively that the strength (or hardness) was mainly affected by the fraction of coarse primary $\alpha$ phase and inter-lamellar spacing of the secondary $\alpha$ precipitates (which was dominated by the cutting mechanism), whereas the elongation was mainly affected by the fraction of secondary $\alpha$ phase, the interspace of primary $\alpha$ and the aspect ratio of primary $\alpha$ phase. Thus, the combination with an experimental work and a machine learning successfully provided quantitative estimation of the dominant modes of mechanical properties in relation to the microstructural factors.

\section{Supporting Information}

Details about tensile properties of the Ti-17(A) alloy are summalized in Table in Supporting Information.

This material is available on the Journal website at https:// doi.org/10.2355/isijinternational.ISIJINT-2021-261. 


\section{Acknowledgement}

This work was financially supported in part by the Amada Foundation (AF-2018026) and a Grant-in-Aid for Scientific Research from the Light Metals Educational Foundation, Inc., Japan.

\section{REFERENCES}

1) C. Leyens and M. Peters, eds.: Titanium and Titanium Alloys, WileyVCH Verlag GmbH, Weinheim, (2003), 12.

2) Y. Kagawa and M. Demura: Mater. Trans., 60 (2019), 169. https:// doi.org/10.2320/matertrans.MPR2018905

3) P. C. Collins, S. Koduri, B. Welk, J. Tiley and H. L. Fraser: Metall. Mater. Trans. A, 44 (2013), 1441. https://doi.org/10.1007/s11661012-1498-5

4) S. Malinov, W. Sha and J. J. McKeown: Comput. Mater. Sci., 21 (2001), 375. https://doi.org/10.1016/S0927-0256(01)00160-4

5) K. X. Wang, W. D. Zeng, Y. Q. Zhao, Y. T. Shao and Y. G. Zhou: Mater. Sci. Eng. A, 527 (2010), 6193. https://doi.org/10.1016/j. msea.2010.06.059

6) H. Matsumoto: ISIJ Int., 61 (2021), 1011. https://doi.org/10.2355/ isijinternational.ISIJINT-2020-598

7) Z. Sun, H. Yang and Z. Tang: Comput. Mater. Sci., 50 (2010), 308. https://doi.org/10.1016/j.commatsci.2010.08.020

8) X. Ma, W. Zeng, Y. Sun, K. Wang, Y. Lai and Y. Zhou: Mater. Sci. Eng. A, 538 (2012), 182. https://doi.org/10.1016/j.msea.2012.01.027

9) T. K. Redden: Beta Titanium Alloys in the 80's, TMS-AIME, Warrendale, PA, (1984), 239.

10) J. Xu, W. Zeng, Y. Zhao, Z. Jia and X. Sun: J. Alloy. Compd., 673 (2016), 86. https://doi.org/10.1016/j.jallcom.2016.02.220

11) Y. Yamabe-Mitarai, S. Kuroda, N. Motohashi, H. Matsumoto, G Miyamoto, E. Chandiran, Y. Yoshida and Y. Itsumi: Mater. Trans., 60 (2019), 1733. https://doi.org/10.2320/matertrans.ME201911

12) F. Pedregosa, G. Varoquaux, A. Gramfort, V. Michel, B. Thirion, O. Grisel, M. Blondel, P. Prettenhofer, R. Weiss, V. Dubourg, J. Vanderplas, A. Passos, D. Cournapeau, M. Brucher, M. Perrot and É. Duchesnay: J. Mach. Learn. Res., 12 (2011), 2825

13) W. G. Burgers: Physica, 1 (1934), 561. https://doi.org/10.1016/ S0031-8914(34)80244-3

14) J. Da Costa Teixeira, B. Appolaire, E. Aeby-Gautier, S. Denis, G. Cailletaud and N. Späth: Mater. Sci. Eng. A, 448 (2007), 135. https:// doi.org/10.1016/j.msea.2006.10.024
15) E. Aeby-Gautier, F. Bruneseaux, J. Da Costa Teixeira, B. Appolaire, G. Geandier and S. Denis: JOM, 59 (2007), 54. https://doi. org/10.1007/s11837-007-0011-x

16) A. Settefrati, M. Dehmas, G. Geandier, B. Denand, E. Aeby-Gautier, B. Appolaire, G. Khelifati and J. Delfosse: Proc. 12th World Conf. on Titanium (Ti-2011), (Beijing), Science Press, Beijing, (2012), 473.

17) R. Shi, N. Ma and Y. Wang: Acta Mater., 60 (2012), 4172. https:// doi.org/10.1016/j.actamat.2012.04.019

18) Y. Kawabe and S. Muneki: ISIJ Int., 31 (1991), 785. https://doi. org/10.2355/isijinternational.31.785

19) T. Kishi, H. Ohyama and K. Kim: Tetsu-to-Hagané, 72 (1986), 123 (in Japanese). https://doi.org/10.2355/tetsutohagane1955.72.1 123

20) T. Horiya, H. G. Suzuki and T. Kishi: Tetsu-to-Hagané, 75 (1989), 2250 (in Japanese). https://doi.org/10.2355/tetsutohagane1955.75.1_151

21) R. Liang, Y. Ji, S. Wang and S. Liu: Metals, 6 (2016), 186. https:// doi.org/10.3390/met6080186

22) T. Furuhara, T. Maki and T. Makino: J. Mater. Process. Technol., 117 (2001), 318. https://doi.org/10.1016/S0924-0136(01)00790-7

$23)$ D. E. Rumelhart, G. Hinton and R. Williams: Nature, 323 (1986), 533. https://doi.org/10.1038/323533a0

24) K. Nakashima, Y. Futamura, T. Tsuchiyama and S. Takaki: ISIJ Int., 42 (2002), 1541. https://doi.org/10.2355/isijinternational.42.1541

25) T. Kitaura, H. Hidaka, T. Tsuchiyama and S. Takaki: Tetsu-toHagané, 91 (2005), 796 (in Japanese). https://doi.org/10.2355/ tetsutohagane1955.91.11_796

26) J. H. Ward, Jr.: J. Am. Stat. Assoc., 58 (1963), 236. https://www.jstor. org/stable/2282967

27) K. C. Russell and L. M. Brown: Acta Metall., 20 (1972), 969. https:// doi.org/10.1016/0001-6160(72)90091-0

$28)$ E. Arzt and M. F. Ashby: Scr. Metall., 16 (1982), 1285. https://doi. org/10.1016/0036-9748(82)90484-7

29) R. Hill: The Mathematical Theory of Plasticity, Oxford University Press, Oxford, UK, (1950), 257.

30) J. B. Liu, M. L. Hou, H. Y. Yang, H. B. Xie, C. Yang, J. D. Zhang, Q. Feng, L. T. Wang, L. Meng and H. T. Wang: J. Alloy. Compd., 765 (2018), 560. https://doi.org/10.1016/j.jallcom.2018.06.158

31) Q. Fang, L. Li, J. Li, H. Wu, Z. Huang, B. Liu, Y. Liu and P. K. Liaw: J. Mech. Phys. Solids, 122 (2019), 177. https://doi.org/10.1016/j. jmps.2018.09.010

32) C. G. Rhodes and N. E. Paton: Metall. Trans. A, 8 (1977), 1749. https://doi.org/10.1007/BF02646879

33) S. X. Liang, L. X. Yin, R. J. Jiang, X. Y. Zhang, M. Z. Ma and R. P. Liu: J. Alloy. Compd., 603 (2014), 42. https://doi.org/10.1016/j. jallcom.2014.03.057 